\title{
APPROACHING NEW PIANO LITERATURE: COMPOSITION AND INTERPRETATION OF FOUR PIANO ETUDES*
}

ENFOQUE DE LA NUEVA LITERATURA DE PIANO: COMPOSICIÓN E INTERPRETACIÓN DE CUATRO ESTUDIOS PARA PIANO

Marco Alunno

Universidad EAFIT, malunno@eafit.edu.co

Andrés Gómez Bravo

Universidad EAFIT, agomezbr@eafit.edu.co

Fecha de recibido: 7 - 10 - 2019

Fecha de aprobación: $12-02-2020$ 
Abstract

In the literature for solo instrument, etudes typically present different kinds of technical and expressive challenges. In fact, they often focus on unique and problematic aspects of performance on a specific instrument. The short group of piano etudes presented here has the same purpose, although, in some cases, it recalls writing techniques and melodic-rhythmical modules usually associated with composers and styles of both the past and present times. In this article in particular, four etudes (Scales, Expressive Fingering, Parallel Thirds and Broken Octaves) are briefly described and analyzed from both a compositional and an interpretive approach, given the case that both the composer and the interpreter were in contact during the creative and learning process of the pieces. The result of this kind of collaboration is twofold: a composition whose playability and effectiveness are warranted by the practice of the interpreter, and a performance with a better understanding of the direct wishes of the composer.

Keywords: piano etudes, performance practice, new music, piano composition.

\section{Resumen}

En la literatura para instrumento solo, los estudios presentan típicamente diferentes tipos de retos tanto técnicos como expresivos. De hecho, frecuentemente se enfocan en aspectos problemáticos de la interpretación de cada instrumento en específico. El pequeño grupo de estudios presentado aquí, comparte el mismo propósito, aunque, en algunos casos, recuerda técnicas y módulos melódico-rítmicos típicamente asociados con compositores y estilos tanto del pasado como del presente. En este artículo en particular, cuatro estudios (Scales, Expressive Fingering, Parallel Thirds and Broken Octaves) se describen brevemente y analizan desde las perspectivas composicional e interpretativa, dada la situación que tanto el compositor como el intérprete estuvieron en contacto durante el proceso de creación y montaje de las piezas. El resultado de este tipo de colaboración es dúplice: por un lado una composición cuya vibilidad técnica y eficacia musical están garantizadas por la práctica del intérprete, y por el otro una interpretación con mejor entendimiento de los deseos del compositor.

Palabras clave: estudios para piano, prácticas interpretativas, música nueva, composiciones para piano. 


\section{Introduction}

\subsection{The composer (Marco Alunno)}

As a former pianist who abandoned his practice to devote uniquely to composing, I confess that a sort of nostalgia for the instrument is present by and then. However, it is related neither to the hours spent learning new pieces and overcoming technical difficulties, nor so much to the sound I was able to produce. It is rather related to the amazingly large number of patterns that fingers can realize on a keyboard and, without daily exercise, I cannot perform anymore. This is a physical pleasure I do not have access to any longer. Fortunately, it is possible to abstract the physical away from the pleasure and find shelter in the pure contemplation of keys' configurations. It might sound a meager consolation but, from a compositional point of view, it opens up a completely different world to imagination.

I do not mean to reduce the beauty of piano playing only to fingers' patterns, but I must admit that that is one of its specificities. In fact, unlike string and wind instruments, a piano is activated only by hands - no air, no bow - that fulfill the same symmetric function: pressing keys. Note that the functions some piano writing assign to each hand (i.e. melody and accompaniment) are referred to a linguistic context, whereas here it is the muscle activity and its abstraction in patterns to be under scrutiny.

I would say that this perspective was the drive that led me to compose eight piano etudes. ${ }^{1}$ Before then, approaching piano writing always felt a little bit daunting: in the spasmodic search of new sounds, I wondered far too much what sound a piano should produce. But, in the end, what other sound a piano should produce but the sound of a piano? Therefore, I found my own answer by focusing on technical aspects of piano playing and letting the piano sounds for what it is. This made sense because technique is tightly connected to how fingers can move on the keyboard. All the more, it imposes upon fingers' patterns a coherent structure, frequently determined by specific sets of intervals. For example, in the case of my etudes: seconds (in Scales), thirds (in Parallel Thirds), perfect fifths (in Arpeggios and Perfect Fifths) and octaves (in Broken Octaves).

In addition to abstract ideas of construction, other elements intervened to mold and smooth out the asperities of pre-compositional principles. Thus, the final shape of each etude is also the product of a combination of different creative patterns. They will be described in the following sections along with the compositional and interpretive strategies that brought to the performance of four of the eight etudes in the collection: Scales, Expressive Fingering, Parallel Thirds and Broken Octaves.

\footnotetext{
Marco Alunno, Piano Études. Medellín (Colombia): Fondo Editorial Universidad EAFIT, 2019. This etudes are dedicated to Andrés Gómez Bravo.
} 


\subsection{The interpreter (Andrés Gómez Bravo)}

I have had the pleasure of performing several of the composer's pieces in my career, most notably, his work for two pianos Journeys and his chamber music piece for flute, clarinet, violin and electronic piano False Start. Even though I have thoroughly enjoyed working on this music, I do have to say that the degree of compositional and technical complexity is very demanding. At the time I was proposed to perform these piano etudes, I was sure that they would be equally challenging. I wasn't wrong.

The history of piano etudes is well known (Gordon, 1996; Kirby \& Hinson, 2004), starting with rather mechanical exercises, to ground breaking technical and musical pieces such as Chopin's etudes 0p. 10 and 0p. 25, Lists's transcendental etudes and the more recent 18 etudes by György Ligeti. All of them share at least two common traits, i.e. their length, usually no more than 5 minutes, and their high technical demands. As pianists, we are used to spending a lot of time mastering these short masterpieces, since we know that each one of them will add refinement to our pianism.

Since one of the main interests of piano etudes is to explore some technical facet of the piano, I will mostly focus my discussion on this aspect. The four etudes exposed in this article deal with rhythmical complexities, scale playing, repeated notes, voicing, legato, and textural intricacies that deserve some preliminary comments for all the pianists who want to approach this new repertoire.

\section{Scales}

\subsection{Composition}

The whole piece develops around a basic idea stated at the beginning of the etude (Fig.1).

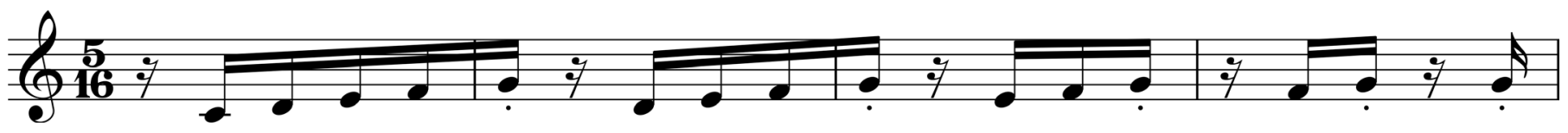

Fig. 1. Main idea in Scales.

However, originally, its rhythm was conceived in a different way (Fig. 2).

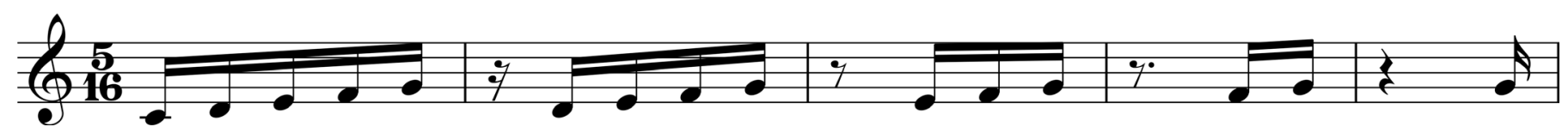

Fig. 2. Original idea in Scales. 
Although the original rhythmic procedure (subtraction and replacement of notes with rests) was more intuitive and simpler from a constructive point of view, the second version (Fig. 1), that adds an extra operation - shifting - to subtraction and replacement, is musically more effective. In fact, it allows the music to flow almost uninterrupted, whereas the increasing separation of fragments in the original idea would hinder the forward motion conveyed by the raising scale.

Transposition, inversion, retrogradation, contraction, expansion, subtraction, addition, both melodically and rhythmically, offer a vast range of tools to manipulate the basic idea, especially when multiple voices contribute to form a thick web of countrapuntal objects. Many of these tools were used to produce an intricate and constantly varied musical surface.

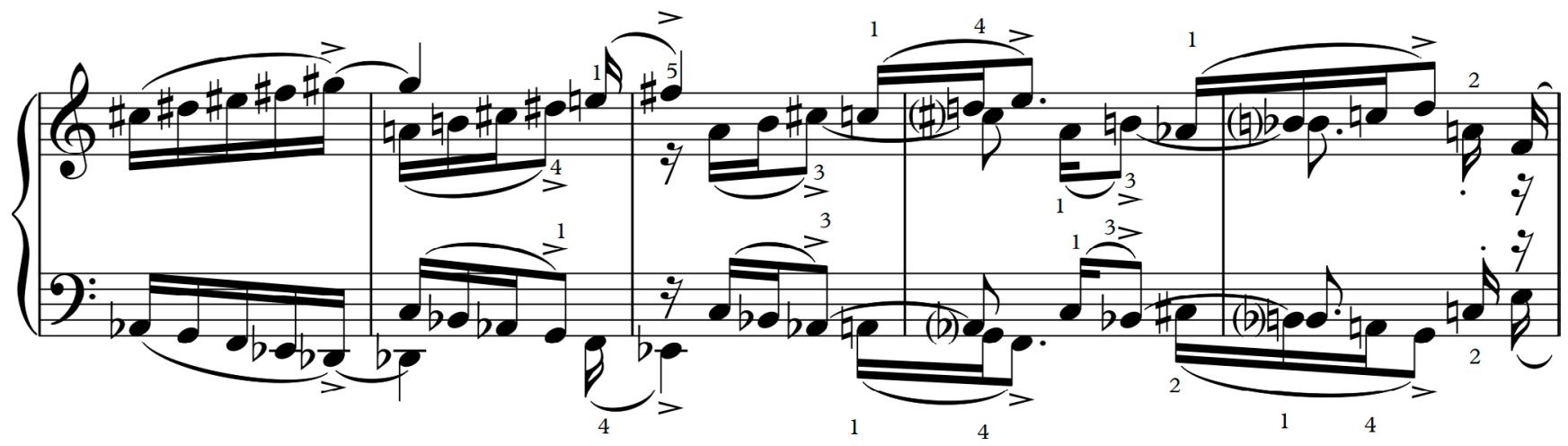

Fig. 3. Contrapuntal web in Scales, mm. 132-136.

Fig. 3 shows an example of contrapuntal texture generated by manipulations of the scale object: the outer voices moves polytonally in contrary motion; thus do the inner voices. However, whereas the outer voices convert one five-sixteenth-long held note into a five-note scale one sixteenth at a time, the inner voices do exactly the opposite: they shorten progressively by converting a five-note scale into one fivesixteenth-long held note.

While composing Scales, I could not miss what subconscious reference might have triggered the idea of such an interplay of voices on a scale pattern. I am talking about the etude No. 13, L'escalier du diable, by Ligeti who is honored both in the dedication of the etude and in the brief use of the Tastenblockierung technique (mm. 145-152). ${ }^{2}$

\subsection{Interpretation}

Scales calls for an even touch but, at the same time, the micropolyphony used, which is its fundamental building block, requires the performer to keep control over each little voice. The piece has to be treated as a fugue, but on steroids! The imitations, as described by the composer, are very tight, so it is fundamental to have a clear sound image of where each little voice is going, thus to make sure that the texture is always

2 An extensive use of blocked keys is found in the second of Ligeti's Three Pieces for Two Pianos (1976). 
clear. The fingerings suggested by the composer work very well, especially when it comes to holding notes while the other voices move. Working with the composer, it became evident that even though he wanted a clear articulation of each note, the forward direction of the scale gestures should not get lost.

There are a few suggestions that, in my concept, would make playing the etude more effective: first, one has to make sure that the rests between groups of notes are clear, especially the rest before the pickup to measure 161 as it introduces the last section of the etude (Fig. 4). Secondly, I suggest to expand the time on the pick up to measure 166, which is the last climax of the piece (not shown here). Lastly, in the section from 128 to 144 (see excerpt in Fig. 3), the pianist should let the tempo be altered by the complexity of the accentuation proposed by the composer, that is to say that the music asks for a slightly slower tempo in order to let the pianist give the right weight to the texture.

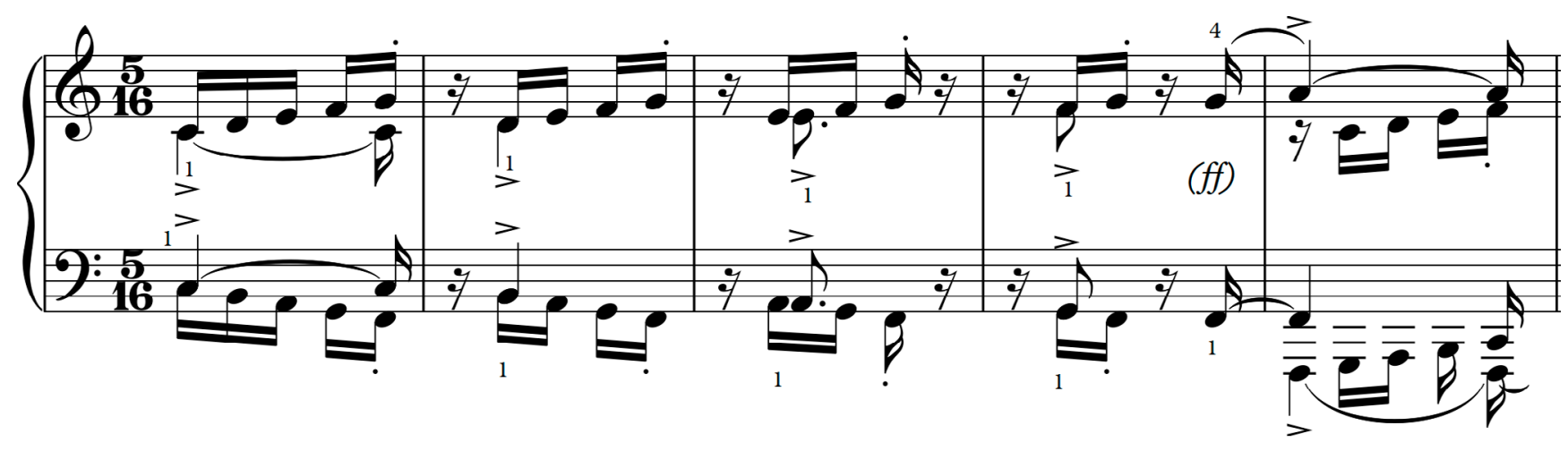

Fig. 4. Pickup to the last section of Scales, mm. 157-161.

\section{Expressive Fingering}

\subsection{Composition}

As far as I know, the initial idea might have come from listening a Bach fugue and paying attention to the circular harmonic progression of the exposition (tonic dominant tonic dominant etc.). What I was consciously looking for was a repeating harmonic pattern, and a fugue exposition just happened to offer that. In order to implement a piano technique upon this simple concept, I found all the more natural to 'overexpress' the contrapuntal writing of a fugue and expect fingers' legato to dovetail each voice stream.

The overall arch-like, formal shape of the etude is due to the increasing number of voices (from 1 to 7, encompassing the full exposition of the fugue) and a mirrorlike decrement (from 7 to 1 , a full reversed exposition). The metronome for each entrance and exit goes, instead, in contrary motion: it gets slower (from 60 to 
36 per quarter note) as voices increase in number and faster (back to 60) when they decrease. Both reversals are reflected also in the inversion the fugue subject undergoes throughout the piece (Fig. 5).

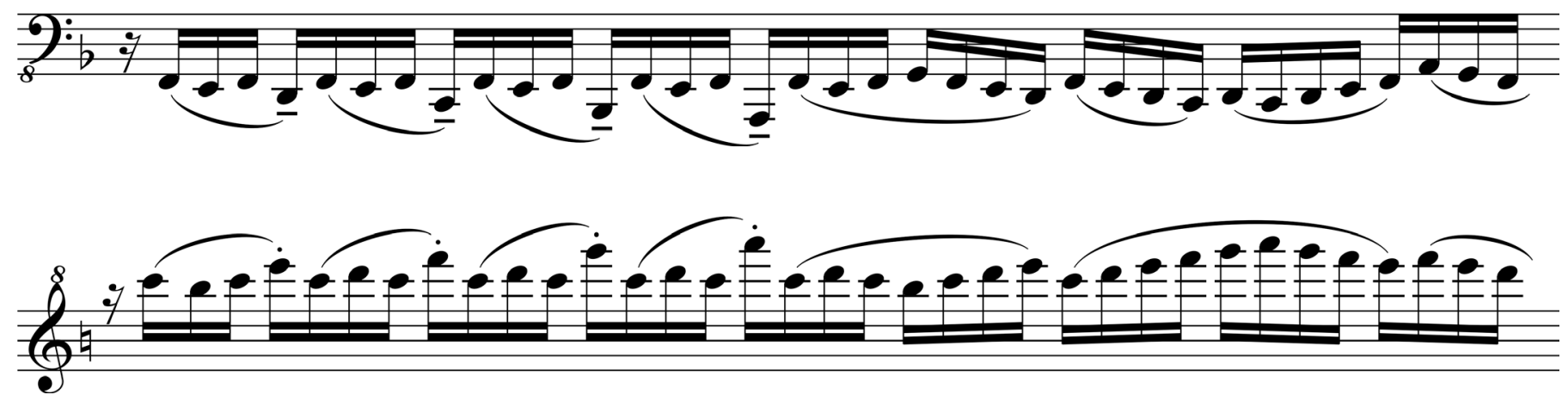

Fig. 5. Subject of the fugue at the beginning of the piece (above) and its inversion at the end (below).

The subject is original, although it clearly recalls typical Bachian melodic patterns in organ pedaling. The answer is real, but a modication of its tail was necessary to allow a modulation from $\mathrm{F}$ to $\mathrm{C}$ and back without having to apply an extension and delaying, thus, the next entrance of the subject. The idea of the progressive transformation of the subject's melodic profile was certainly inspired by how Sofia Gubaidulina treats Bach's Musikalisches Opfer's theme in her violin concerto Offertorium (Gubaidulina, 1980). In this piece, the composer builds a series of variations on Bach's theme and, at each variation, the theme is deconstructed one note at the time and reconstructed back. Thus, as the title suggests, the theme offers itself and comes back to life by mislaying and regaining pieces of its own body. Whereas Gubaidulina took a spiritual reading of the word 'offer,' in my etude, the fugue subject does not immolate itself, but it is more prosaically morphed into its own inversion. Such a morphing, though, is not entirely devoid of spiritual accents, for the final, eccentric sprint of the etude is also a leap into the unknown (Fig. 6).

(as fast as possible)

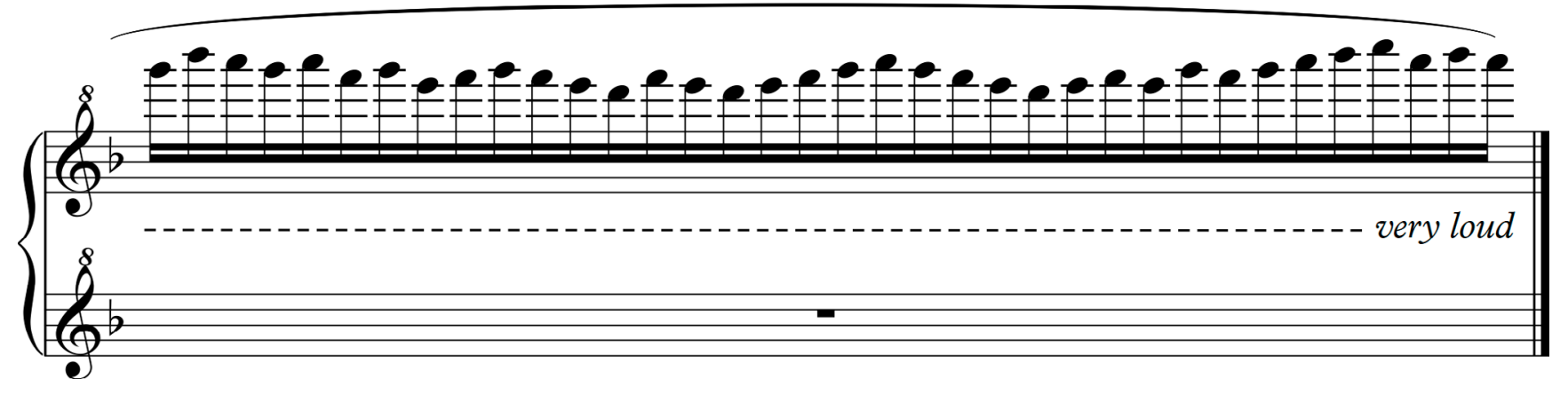

Fig. 6. Final rush at the end of Expressive Fingering. 
In fact, the concrete finiteness of a piano keyboard necessarily limits the impulse that pushes the fugue subject well beyond the last key, into the infinite. Moreover, notice that the linear process that transports the subject (and its answer) across the whole keyboard contrasts the binary, closed form of the etude and provides a window on the future. Thus, the unexpected interruption at the end of the piece (Fig. 6) is a gesture of resignation provoked by many frustrated attempts to break the frontier of physical and formal limitations.

Additionally, in order to resist the highly repetitive nature of the harmonic plan of the piece, I was induced to characterize each repetition in a little extravagant way. I assigned to each phrase a character indication (e.g. "Imperative", "Confident", "Pompous") that should suggest the performer a possible interpretation of the music. This is how an exercise fingers' legato acquires expressivity, as the title of the etude reminds the performer.

\subsection{Interpretation}

Expressive Fingering is more complex to play than it sounds. Even though the tonal language is very close to our ear because of the obvious reference to Bach, two features make it difficult to learn. On the one hand, when we think that at the pinnacle of the piece there are seven voices in contrapuntal motion and human beings only have ten fingers, it is quite obvious that some of them have to be doubled or tripled. This creates a problem when reading and playing it, since it is difficult to keep track visually, aurally and manually (referring to the feeling given by depressing the keys) of where each voice is. The second difficulty is that the composer calls for no pedal during the entire etude, which means that all the legato has to be made with the fingers. There are passages where, given the disposition of the voices, it is just not possible to keep them pedalfree; thus, some syncopated pedals can rescue the performer. In other passages a little pedal can help sustaining the resonance of the instrument. In general, the reasoning behind pedaling in this piece resides in the regular path the etude follows throughout: from the lowest register at the beginning of the piece, where any pedal would mud the texture, to the highest register of the piano, where some pedal can definitely help in moistening the otherwise very dry sonority of the instrument. 


\section{Parallel Thirds}

\subsection{Composition}

As the subtitle of the etude says ("Vallenato chévere"), the piece was inspired by the typical folk music originated in the northern Caribbean region of Colombia. ${ }^{3}$ Although I have neither feeling nor taste for folk music in general, at the time I was about to conceive a new etude for piano, a friend of mine had just lent me a collection of 6 CDs with vallenato music. I listened to most of them and I concluded that, indeed, I could compose something based on a specic feature of that music: sequences of thirds as they are played by the accordion, one of the three characteristic instruments in vallenato music. ${ }^{4}$ Not particularly related to keys distribution in diatonic accordion, thirds are just a typical way a doubling melody in vallenato, and also a good exercise for hands' transversal motion on a piano keyboard. Now, what makes really hard to play parallel intervals on a piano is, of course, the speed the composer asks for (indeed, the character indication for Parallel Thirds is "hogwild"). Whoever played as a student the beginning of both the first and fourth movement from Beethoven's sonata Op. 2 No. 3 knows very well what I am talking about.

The speed required to play my etude was not designed to make pianists' life miserable, it was rather intended to imitate the sound of the puya, which is one of the four 'airs' or possible rhythmic structures in vallenato music. The puya in particular is in $6 / 8$ and is the fastest of the four airs, hence its use in vallenato's festivals and competitions where the accordionist can show off in solo passages of extreme virtuosity.

In Parallel Thirds, the 6/8 meter is frequently reinterpreted as its non-compound version of $3 / 4$. Their alternation in the melodic line reflects the metric ambiguity of bambuco, a genre of Colombian folk music from the Andean region. However, whereas in bambucos polymetry may be found between the melody (in 6/8) and its accompaniment (in 3/4), in Parallel Thirds this principle is extended to the combination of odd meters (such as 6/8 and 3/4) in the melodic line and even meter (4/4) in the harmonic progression (Fig. 7).

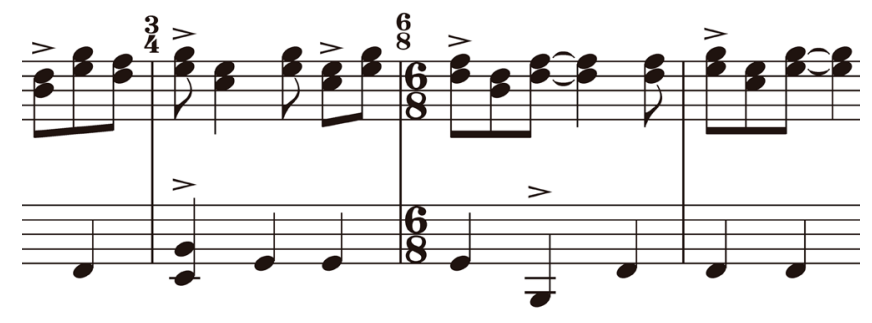

Fig. 7 Polymetry and heterometry in Parallel Thirds, mm. 30-31.

\footnotetext{
3 The word "chévere" is just a Colombian slang expression that means cool.

4 The other two are the caja vallenata (a small drum) and the guacharaca (a scratch-sounding percussive instrument similar to the güiro).
} 
As specified in a footnote in the score, accent should help mark the subdivision of the measures and the length of the rhythmic patterns rather than represent a true accentuation.

In Fig. 8 one can also observe that, as the harmonic progression reflects the typical simple scheme (I-V-I) of much of folk music, the obvious result of the difference of durations between melodic and harmonic layers yields recurring polytonality, namely when dominant harmony is overlapped to the tonic chord implied in the melody. Yet, polytonality is sometimes explicitly sought for (Figs. 8-10):

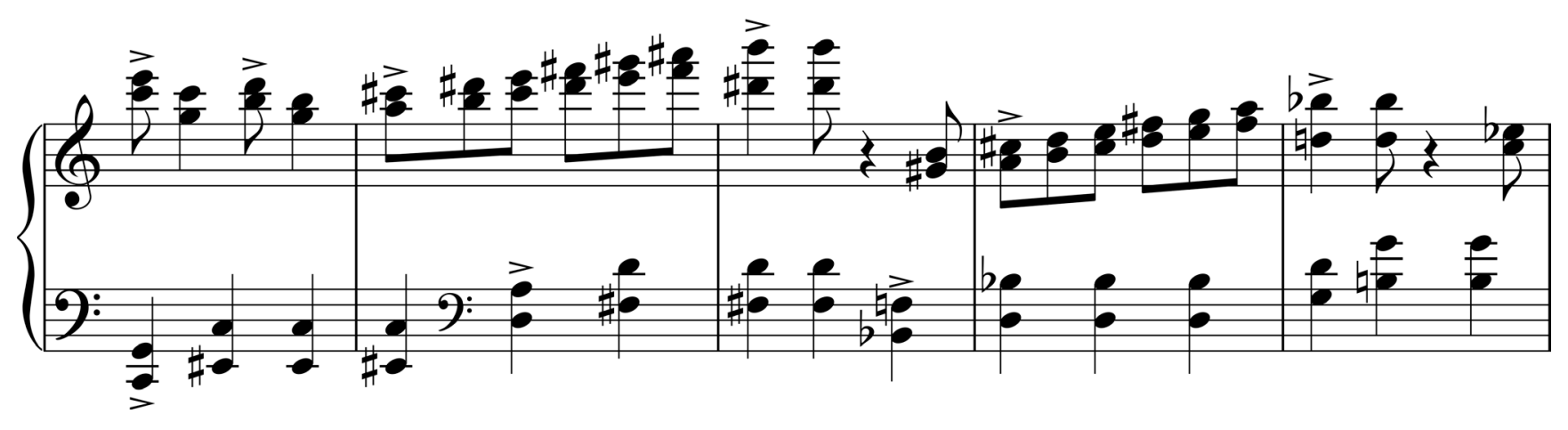

Fig. 8. Polytonality in Parallel Thirds, mm. 35-39.

The disorientation generated by polytonality is quickly transformed into clusters, first in the lowest four piano keys only,

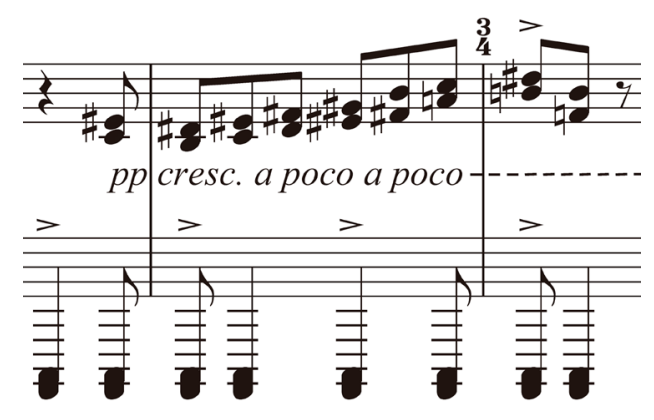

Fig. 9. Clusters in the left hand, m. 55.

and eventually in both hands all over the piano keyboard: 


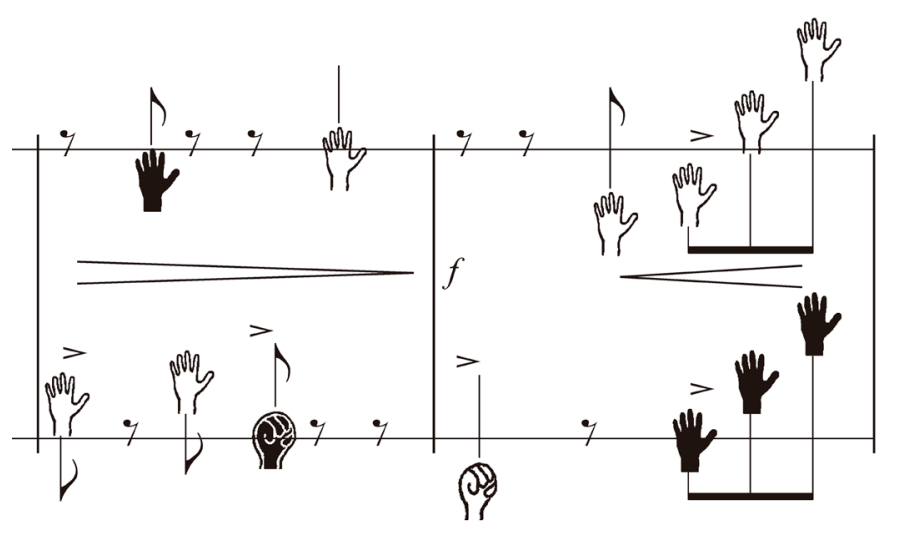

Fig. 10. Graphic notation for different kinds of clusters, mm. 74-75.

Once peace has been reestablished, the initial melody comes back in, tripled in parallel major and minor triads (Fig. 12). A perfect cadence in C closes the piece.

\subsection{Interpretation}

As required by the composer, the speed marked in this etude is almost unattainable. The accordion, whose agility inspired this piece, can play three notes by just depressing one key, which sets the speed limit for that instrument extremely high. On the other hand, the piano and the pianist have two limitations: the mechanics only let to repeat the same key at a certain speed and the lateral movements that are required to play the etude also impose some physical limitations. All of this is to say that if the etude has to be played as fast as possible by the performer, there is no speed at which the piece would be considered too fast. The indication by the composer is to play nonlegato, which makes it especially beneficial when there are two or three notes to be played at the same time by the same hand. However, since the accentuation in the right hand is in $6 / 8$ and $3 / 4$ while the left hand is in $4 / 4$, as mention before, the rhythmical complexities are difficult to coordinate.

As per my own interpretation, after a diverging glissando with both hands (that ends the section briefly exposed in Fig. 11) expands out from the middle of the keyboard and brings back to the tempo primo, the minimalist pattern that transitions into the main theme should start slower and get into the tempo by the recapitulation while letting the resonance yielded by the glissando die out by slowly lifting the pedal (Fig. 11). 


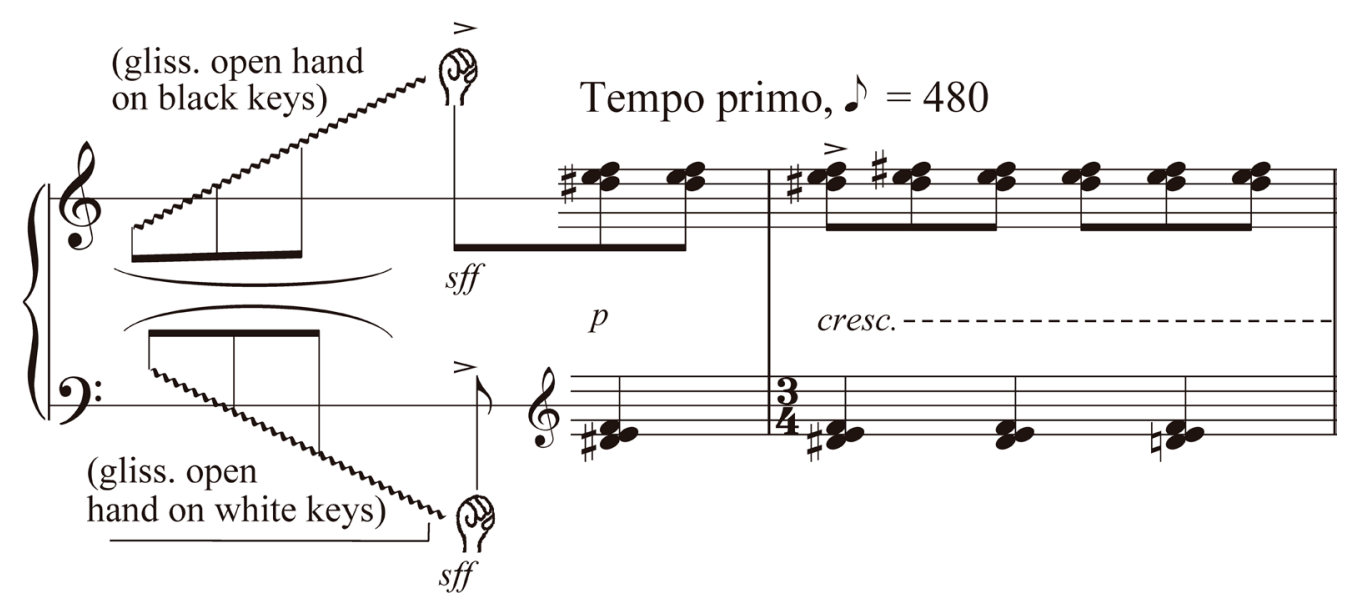

Fig. 11. Glissando and pattern leading into the recapitulation, mm. 84-85.

In the last section, where the melodic patterns move by triads, I do not exclusively use the same fingering for every chord. In fact, the leaps make it almost impossible to do so. Rather, I use a combination of 1-2-3, 1-2-4 and 2-3-5 fingering to bridge the leaps, always aiming for the fastest way possible to overcome the passage, thereby resembling the pace of the puya (Fig. 12).

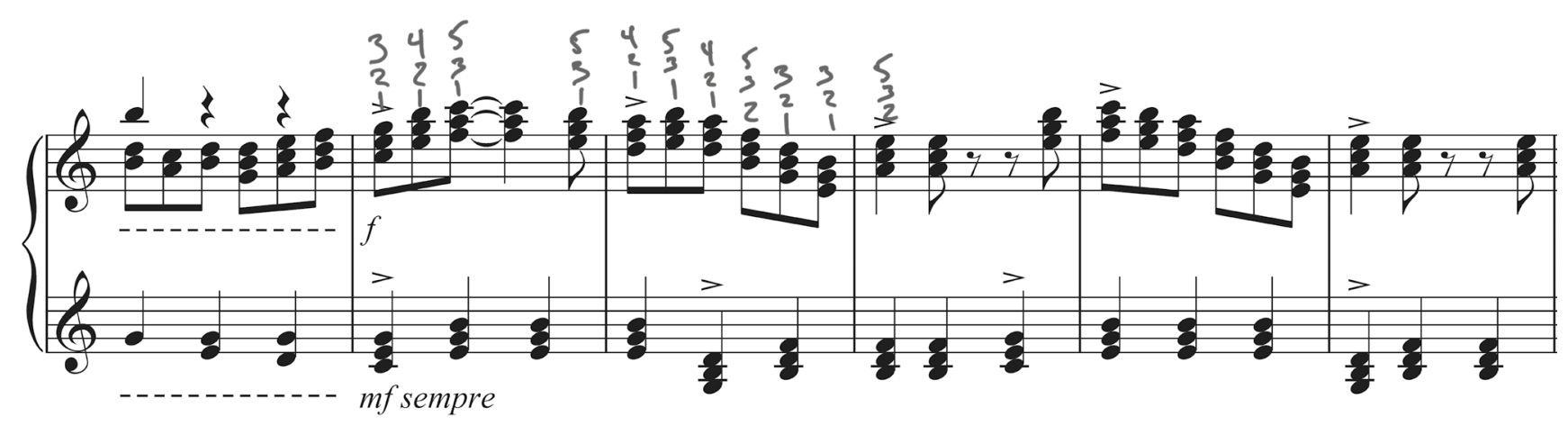

Fig. 12. Recapitulation with parallel triads and manuscript fingerings, mm. 96-101.

\section{Broken Octaves (D'aprés Super Mario Bros.)}

\subsection{Composition}

This is not an homage to Koji Kondo, the iconic composer of video game music for the first Nintendo consoles back in the 1980s. This is not an homage simply because in my youth I never played with a Nintendo, thus my acquaintance with that music world is relatively supeficial. It is just that while thinking of the broken octaves technique 
in the piano, I could not prevent myself from recalling one of the many well-known themes Kondo composed in 1985 for the video game Super Mario Bros., namely the Underground Theme (Fig. 13).

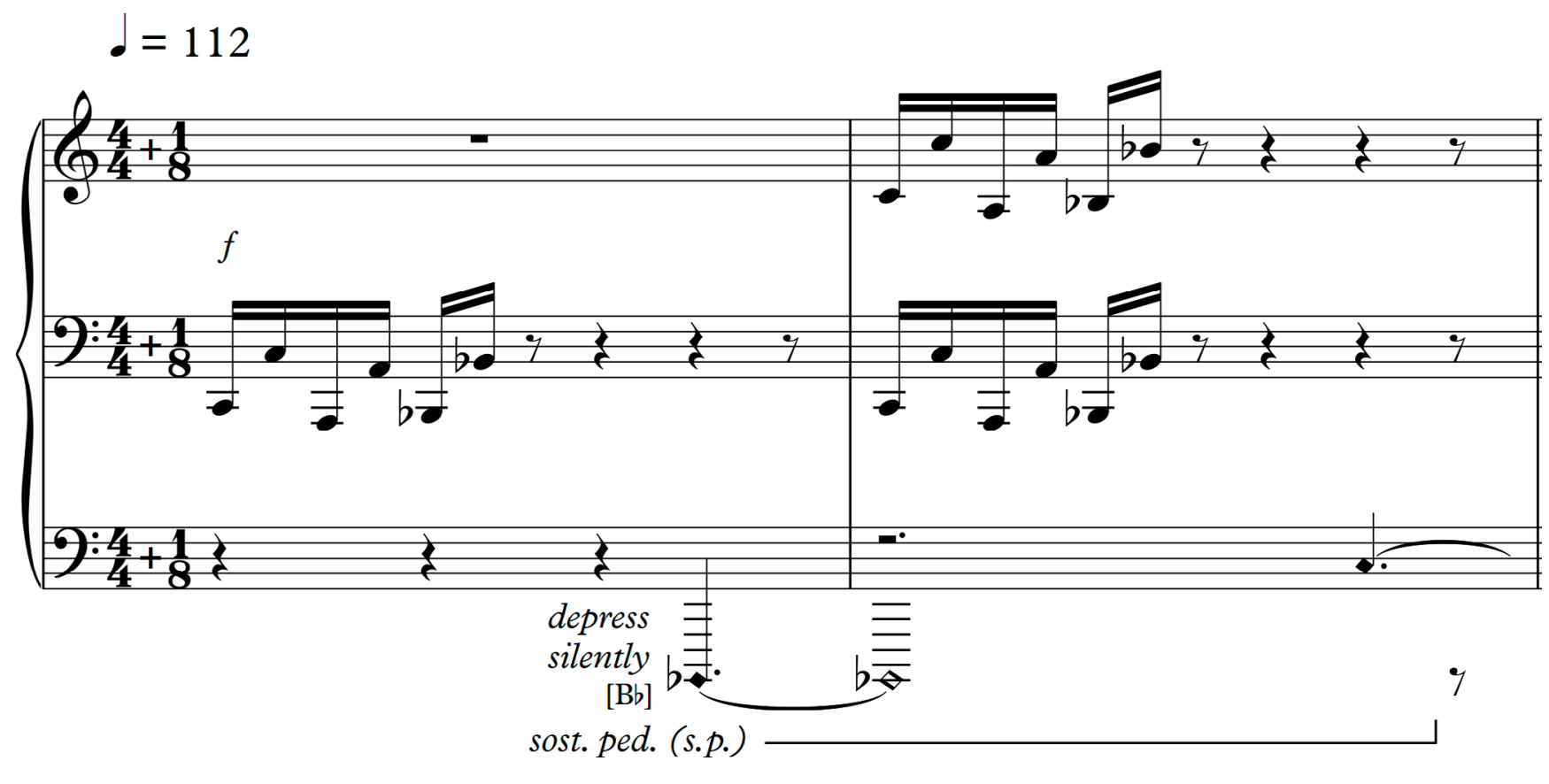

Fig. 13. Transcription of the Underground Theme in Broken Octaves, mm. 1-2.

If one expects to listen to only tonal music in video games, he/she might be surprised at the chromatism of the Underground Theme. In fact, not only the melodic profile of the theme's head reminds of set classes of Webernian flavor (in this case SC 3-2 (013)), but the whole theme, despite a clear descending pitch-interval-7 relationship (if dominant to tonic or tonic to subdominant it is hard to say), is highly chromatic. Thus is my etude, while it develops through transformations and imitations of the theme's head, the only portion of the Underground Theme used in the piece. Of that theme the etude ineherits also a clear robotic pace that is willfully called for in the last section based on inversional imitiation between the two hands. This passage, shown in Fig. 14, brings to a paroxysmal and unhinged finale that dies out on the thin thread of a piano resonance (Fig. 15). 


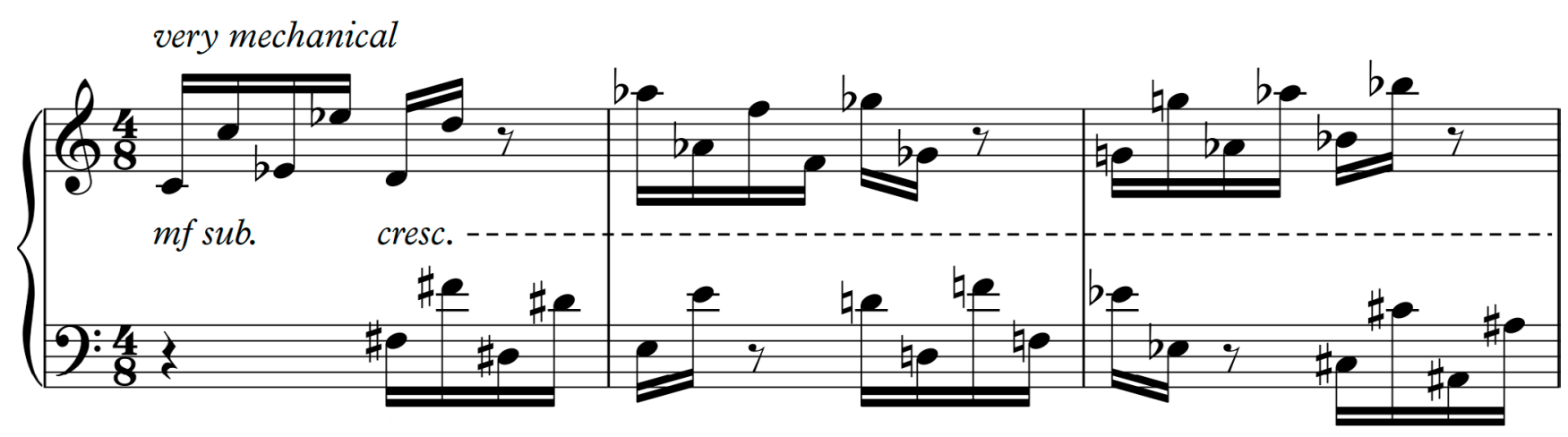

Fig. 14. Robotic passage in inverse canon in Broken Octaves, mm. 57-59.

Finally, observe also how peculiarly the piano sonority is treated with respect to the sound world of Super Mario Bros.: whereas the latter was costrained to produce only so-called 8-bit (or chip) music, the former adds to it the resonance that that technology could not provide. The dry, assertive incipit of the Underground Theme, enhanced by the sharp decay of the 8-bit sounds is counteracted by the ghostly contrail left by the sostenuto pedal and the muted keys in Broken Octaves (Fig. 13 and 15).

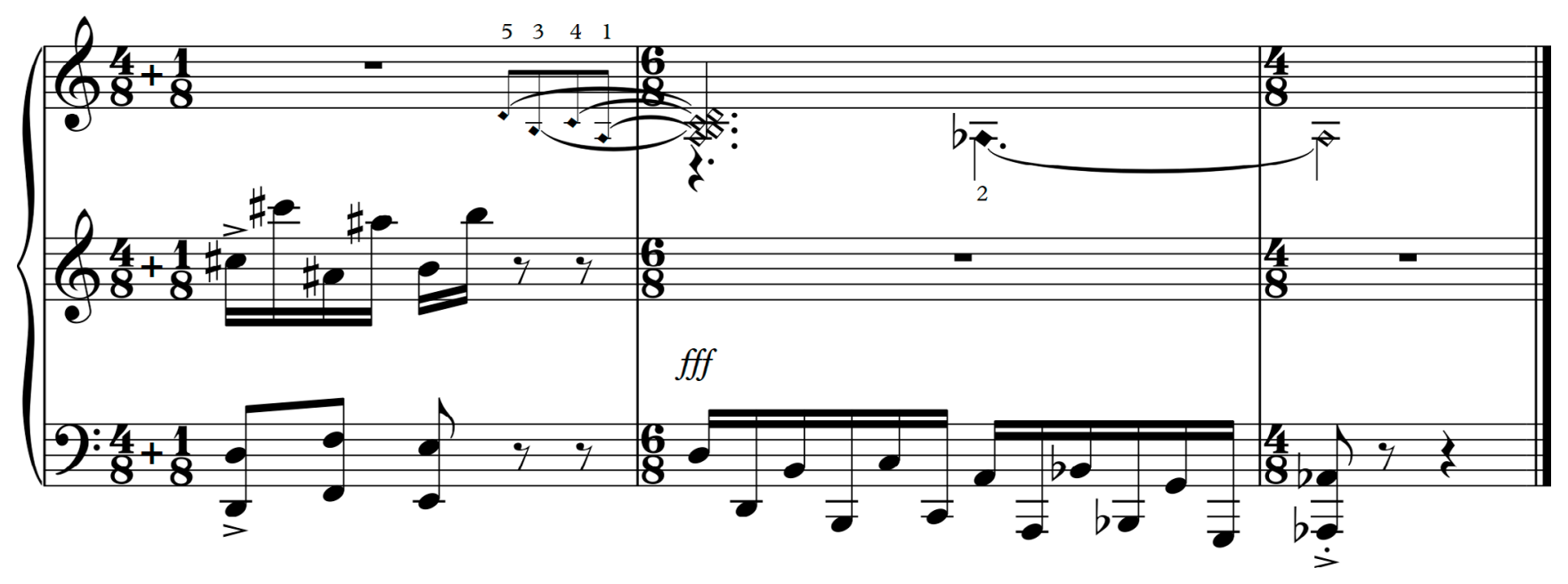

Fig. 15. Finale of Broken Octaves with resonance effect, mm. 92-94.

\subsection{Interpretation}

This etude provides several interesting diculties. First, we have the obvious ones derived from playing an octave etude, which include lateral movements and coordination of the two hands. Second, we have the broken octave, which in this piece move in both directions (up-down and down-up) and includes several triplets as a contrast to duplets. 
The third problem is the accentuation, particularly in the section that starts in measure 26 and deals with an F\#-G-A melodic profile intertwined with triplet movements that expands beyond an octave interval (Fig. 16).

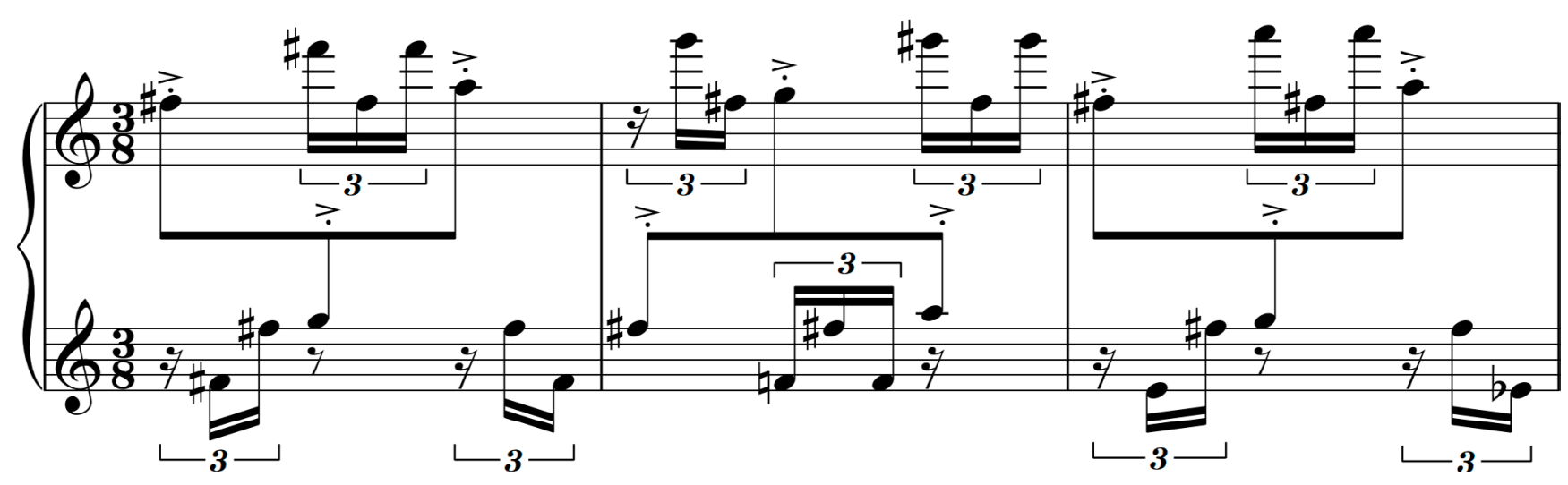

Fig. 16. Intertwined articulation between hands in Broken Octaves, mm. 27-29.

Finally, and perhaps most interestingly, there is the fact that the composer uses the harmonic resonance of the piano as a fundamental tool of composition. This is seen in the use of the middle pedal while silently depressing the keys. In my opinion, this etude is a better teaching piece for this specific skill than any other in the repertoire I know, except possibly for Lachenmann's Serynade (Lachenmann, 2002). The difficulty of this technique increases as the etude unfolds: at first, the performer has to cope only with holding one key silently followed by depressing the middle pedal; the number of silent keys, though, increases later to two or more notes. With regard to this, the most difficult place is probably from measure 50, where a sequence of notes that have to be played silently in the left hand comes while the right hand goes up in broken octaves (Fig. 17).

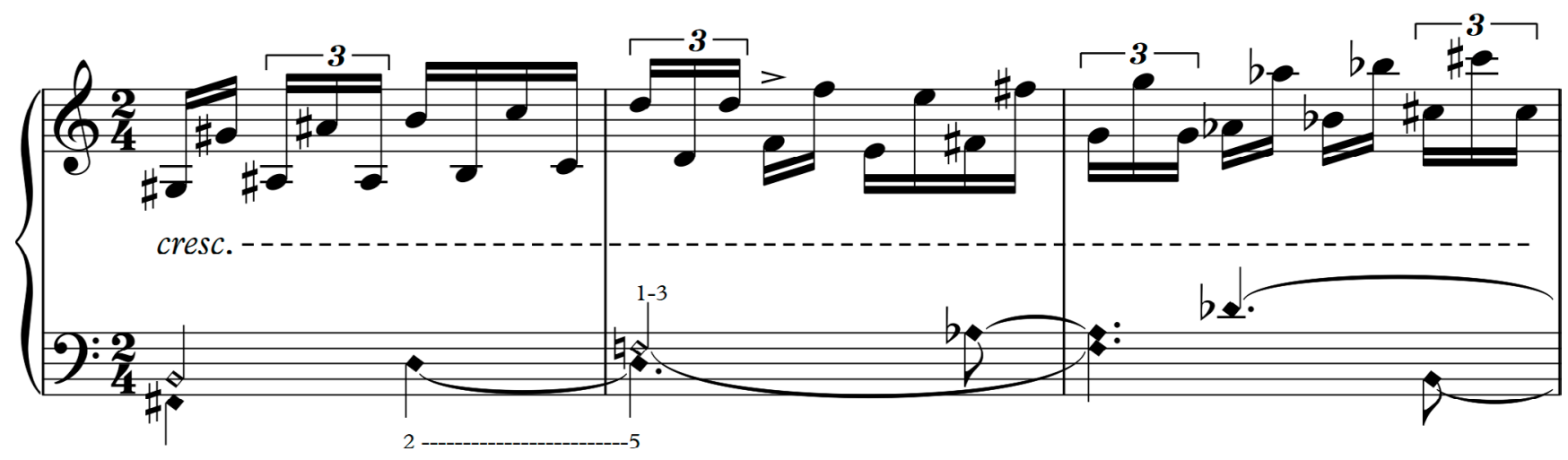

Fig. 17. Sequence of silent keys in Broken 0ctaves, mm. 51-53.

It is important to mention that this aspect makes the etude very risky or impossible to play, since a proper performance depends on the perfect functioning of the 
mechanism of the piano and on the presence of the middle pedal that some older instruments do not have.

\section{Conclusions}

As a composer and former pianist, I perfectly know that four eyes and four ears work better than two. No matter how deep may be my knowledge of the instrument, I was never meant to be the interpreter of these etudes. In such a situation, imagination tends to fly high, especially if one is fiercely pursuing an idea and intends to have it at all costs. Even my old music companion, the piano, all of a sudden may seem to have more sound capacities than it actually has. Therefore, having at your side someone with all the interest in making things work fine (in the end, the interpreter is the one who put themselves on the stage), helps in bringing 'Pindaric flights' down to earth.

From the interpreter's point of view, the discussions I had with the composer during the process of learning his etudes were always enlightening, not only because they clarified some of the patterns and notes in the score, but because they gave me a better understanding of the type of sound and aesthetic approach he wanted. The product of this collaboration (along with other three of the eight etudes in the collection) can now be heard in the CD Tendencias e Inuencias: piano en EAFIT, a project where I had the privilege of counting on the composer during the recording sessions and edition.

These etudes are an excellent addition to the repertoire. They deal with some common technical problems such as fingers' independence in Scales, parallel thirds playing in the Vallenato chévere, legato playing and voice leading in Expressive Fingering, and broken octave playing in the Super Mario Bros. etude. They also deal with other interesting aspects such as micropolyphony, rhythmical complexities, management of different registers on the piano, use of the middle pedal and silent playing. Besides the obvious teaching value, they, along with the other four etudes not presented here, are proper concert pieces that should be included in normal programming.

\section{References}

Alunno, M. (2019). Piano Etudes. Medellín, Colombia: Editorial Universidad EAFIT.

Gordon, S. (1996). A history of keyboard literature: Music for the piano and its forerunners. New York: Schirmer Books.

Gubaidulina, S. (1990). Offertorium. Moscow: Sovestky Kompozitor Publishers.

Kirby, F. E., \& Hinson, M. (2004). Music for piano: A short history. Pomptom Plains, New Jersey: Amadeus.

Lachenmann, H. (2002). Serynade. Wiesbaden, Germany: Breitkopf \& Härtel. 